\title{
Aberrant expression of cell cycle regulators in Hodgkin and Reed-Sternberg cells of classical Hodgkin's lymphoma
}

\author{
Alexandar Tzankov ${ }^{1}$ Annette Zimpfer ${ }^{1,2}$, Philip Went ${ }^{2}$, Robert Maurer ${ }^{3}$, Stefano A Pileri ${ }^{4}$, \\ Stephan Geley ${ }^{5}$ and Stephan Dirnhofer ${ }^{2}$ \\ ${ }^{1}$ Institute of Pathology, Medical University of Innsbruck, Austria; ${ }^{2}$ Institute of Pathology, University of Basel, \\ Switzerland; ${ }^{3}$ Institute of Pathology, Triemli Hospital, Zurich, Switzerland; ${ }^{4}$ Chair of Pathologic Anatomy $\mathcal{E}$ \\ Lymphoma Unit, Institute of Hematology and Clinical Oncology 'L. \& A. Seràgnoli', University of Bologna, \\ Italy and ${ }^{5}$ Institute of Pathophysiology, Medical University of Innsbruck, Austria
}

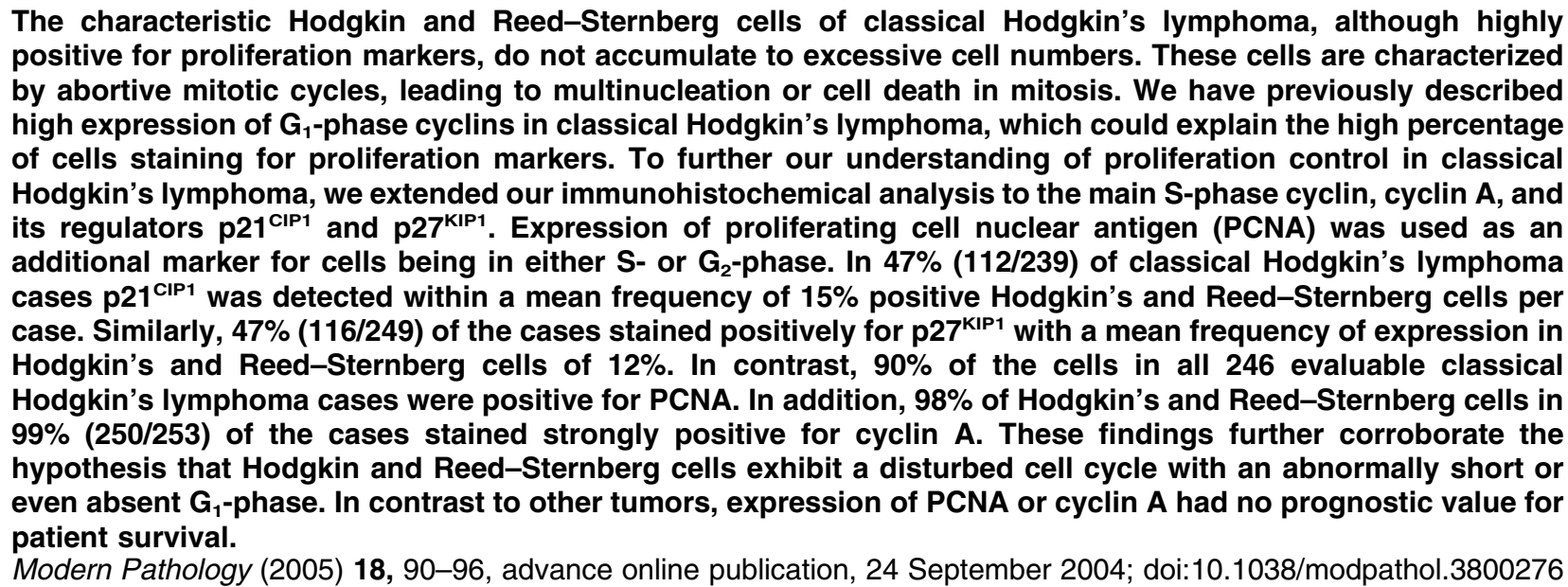

Keywords: cyclin A; cyclin-dependent kinase inhibitors; Hodgkin's lymphoma; PCNA; p21 ${ }^{\text {CIP1; }}$ p27 ${ }^{\text {KIP1; }}$ tissue microarray

The Hodgkin and Reed-Sternberg cells of classical Hodgkin's lymphoma exhibit a proliferation defect caused by abortive mitotic cycles, the latter characterized by abnormal metaphase to anaphase transitions as well as by cytokinesis defects, which may cause multinucleation, polyploidy or mitotic cell death. ${ }^{1,2}$ This mitotic defect could at least partially explain the discrepancy between the high expression of proliferation-associated antigens, such as Ki-67, in Hodgkin and Reed-Sternberg cells and the concomitant lack of successful tumor-cell

Correspondence: Dr S Dirnhofer, MD, Institute of Pathology, University of Basel, Schönbeinstrasse 40, CH-4031 Basel, Switzerland.

E-mail: sdirnhofer@uhbs.ch

Received 5 May 2004; revised 9 August 2004; accepted 10 August 2004; published online 24 September 2004 production. ${ }^{2-4}$ In addition, Reed-Sternberg cells are polyploid and probably amplify their genome by skipping cytokinesis to repeatedly switch between S-phase and mitosis. ${ }^{5}$

We recently demonstrated alterations in the expression of $G_{1}$-phase cyclins in classical Hodgkin's lymphoma, particularly that of cyclin $E,{ }^{6}$ the high expression of which led us to conclude that Hodgkin and Reed-Sternberg cells either have a particularly long $G_{1}$-phase or express an abnormally stable cyclin E, which is not degraded in S-phase cells. To distinguish between these possibilities, we investigated genes known to be expressed in nonproliferating cells, such as the cyclin-dependent kinase inhibitors $\mathrm{p} 27^{\mathrm{KIP} 1}$ and p21 $1^{\mathrm{CIP} 1}$, as well as genes typically expressed in proliferating cells, such as cyclin A and proliferating cell nuclear antigen (PCNA). 
The cyclin-dependent kinase inhibitors p27 ${ }^{\mathrm{KIP} 1}$ and $\mathrm{p} 21^{\mathrm{CIP} 1}$ act by binding to and inhibiting the cyclin $\mathrm{E}$ and cyclin A-activated cyclin-dependent kinase 2, thus controlling entry into S-phase. ${ }^{7-9}$ Both cyclin-dependent kinase inhibitors are controlled at multiple levels and coordinate cellular proliferation by integrating extracellular as well as intracellular cues (reviewed in Sherr and Roberts ${ }^{10}$ ). In contrast to p27 ${ }^{\mathrm{KIP} 1}$, which becomes unstable once cells enter S-phase, p2 $1^{\mathrm{CIP} 1}$ can be induced at any time during the cell division cycle in p53-dependent as well as independent manners, and controls not only the $\mathrm{G}_{1}$ to S-phase transition, but also progression through S-phase as well as entry into mitosis. ${ }^{7,9,11,12}$ During S-phase, p21 ${ }^{\text {CIP1 }}$ is able to associate with the DNA clamp protein PCNA to control the activity of DNA polymerases. ${ }^{8,10}$

Progression through $S$ - and $G_{2}$-phase and entry into mitosis are controlled by cyclin $\mathrm{A}$, which becomes detectable as cells enter S-phase (reviewed in Gillett and Barnes ${ }^{13}$ and Sherr ${ }^{14}$ ). Cyclin A levels and associated cyclin-dependent kinase 2 activity steadily increase during S-phase until prometaphase, when cyclin A becomes an unstable protein. ${ }^{15,16}$ Cyclin A can, therefore, be regarded as a marker for cells in $S$ - or $G_{2}$-phase of the cell cycle. Similarly, PCNA is extensively used (together with Ki-67) as a marker for cells in S- or $G_{2}$-phase of the cell division cycle.

To investigate the mechanisms that control cell cycle progression during the $\mathrm{S}$ - and $\mathrm{G}_{2}$-phase and to further characterize cell cycle regulation in Hodgkin and Reed-Sternberg cells, we performed immunohistochemical analyses of $\mathrm{p} 21^{\mathrm{CIP} 1}, \mathrm{p} 27^{\mathrm{KIP} 1}$, cyclin A and PCNA expression on our previously validated tissue microarray encompassing 330 cases of classical Hodgkin's lymphoma. ${ }^{6,17}$

\section{Materials and methods}

\section{Patients}

A total of 330 paraffin-embedded classical Hodgkin's lymphoma tissue samples ${ }^{6}$ were included in this study, covering all histological subtypes of the World Health Organization classification. ${ }^{18}$ They comprised 197 nodular sclerosis, 105 mixed cellularity, 10 diffuse and nodular lymphocyte-rich and five lymphocyte-depleted as well as 13 unclassifiable classical Hodgkin's lymphoma cases. In 107 patients, aged between 12 and 87 years, clinical follow-up data were obtained by reviewing the charts (Table 1). Treatment was either standard or consistent with the investigational protocols active during the time the patients were diagnosed. Disease remission was defined as absence of disease for at least 1 month after the last treatment regimen ended, as assessed by laboratory and imaging studies and physical examination. Disease relapse was defined as disease progression after at least 1 month of disease remission. Nine patients died due to treat-
Table 1 Clinicopathological characteristics of classical Hodgkin's lymphoma patients with follow-up

\begin{tabular}{lcc}
\hline Patients (n) & $\mathrm{n}$ & $\%$ \\
\hline Histology (107) & & \\
$\quad$ Nodular sclerosis & 63 & 59 \\
Mixed cellularity & 32 & 30 \\
Lymphocyte-depleted & 3 & 3 \\
Lymphocyte-rich & 1 & 1 \\
Unclassified & 8 & 7 \\
Sex (107) & & \\
Male & 56 & 52 \\
Female & 51 & 48 \\
Ann-Arbor stage (91) & & \\
I-II & 55 & 61 \\
III-IV & 36 & 39 \\
Mean age (years) (107) & & \\
& & \\
Therapy (102) & & \\
Radiotherapy & & \\
Chemotherapy/radiochemotherapy & 23 & 23 \\
& 79 & 79 \\
B-symptoms (99) & & \\
Median follow-up, months (107) & $145(5-331)$ & 40 \\
Dead with/on disease (107) & 9 & 8 \\
Disease relapses (102) & 28 & 26 \\
& & \\
\hline
\end{tabular}

ment failures (eight relapses, and one resistant disease), 11 due to histologically documented second malignancies without evidence of persistent Hodgkin's lymphoma and seven due to cardiovascular emergencies. Within the median follow-up period of 145 months, cumulative disease-specific survival was $92 \%$, whereas overall survival was $75 \%$.

\section{Construction of Tissue Microarrays and Morphological Analysis}

The construction of tissue microarray was performed as described previously. ${ }^{6,17}$ Sections of the tissue microarray blocks, $4 \mu \mathrm{m}$ thick, were transferred to an adhesive-coated glass slide system (Instrumedics Inc., Hackensack, NJ, USA) and stained with hematoxylin and eosin, Giemsa and with the periodic acid Schiff reaction. Only cases containing at least two morphologically unequivocal Hodgkin and Reed-Sternberg cells were analyzed.

\section{Immunohistochemistry}

Bound secondary antibodies were visualized by standard avidin-biotin-peroxidase technique using diaminobenzidine as chromogene. Commercially available primary antibodies against p21 $1^{\mathrm{CIP} 1}$ (DAKO, dilution 1:40), p27 $7^{\mathrm{KIP} 1}$ (DAKO, dilution 1:100), PCNA (DAKO, dilution 1:300) and cyclin A (Neomarkers, dilution 1:500) were applied. Nuclear staining 
was quantified as percentage of positive Hodgkin and Reed-Sternberg cells' nuclei in out of all detectable tumor cells. To estimate the prognostic value of cyclin-dependent kinase inhibitors, the cases were grouped in negative and positive cases with a cutoff level of expression in $\leqslant 10 \%$ of the Hodgkin and Reed-Sternberg cells, or, in cases with less than 10 Hodgkin and Reed-Sternberg cells, $\leqslant 50 \%$. In the negative control experiments, the primary antibodies were omitted.

\section{Statistics}

Statistical analysis was performed applying the Statistical Package of Social Sciences. The Spearman's rank correlation and the Pearson's $\chi^{2}$ tests were used to demonstrate correlations between the expression of p21 ${ }^{\mathrm{CIP} 1}, \mathrm{p} 27^{\mathrm{KIP} 1}$, PCNA and $\mathrm{G}_{1}$-cyclins as well as association with Epstein-Barr virusinfection. Disease-specific- and overall survival were analyzed by the Kaplan-Maier method and compared by the log-rank test. Multivariate analysis for the prognostic significance of the expression of p2 $21^{\mathrm{CIP} 1}$, p2 $7^{\mathrm{KIP} 1}$ and PCNA as well as for age, sex, Ann-Arbor stage, Epstein-Barr virus-infection, B-symptoms, disease relapses and therapy was performed using a Cox stepwise regression model. $P$-values below 0.05 were considered significant.

\section{Results}

\section{Histopathology}

Of 330 classical Hodgkin's lymphoma cases included in the tissue microarrays, $260(79 \%)$ were representative by hematoxylin and eosin morphology. The analysis failure of 70 cases (21\%) was linked to problems associated with the array technology, as discussed recently. ${ }^{6,17}$ The evaluable cases consisted of 152 nodular sclerosis, 84 mixed cellularity, nine lymphocyte-rich, five lymphocytedepleted and 10 unclassifiable classical Hodgkin's lymphomas comprising a total mean number of 10243 Hodgkin and Reed-Sternberg cells per slide. Five cases of nodular sclerosis classical Hodgkin's lymphoma were inadequately fixed and, therefore, immunohistochemical examinations could be performed on 147 nodular sclerosis cases. Cores containing 'no tissue' varied from slide to slide. Thus, the evaluation of cases containing diagnostic Hodgkin and Reed-Sternberg cells changed accordingly compared to previous studies with these tissue microarrays. ${ }^{6,17}$

\section{Immunohistochemical Analysis}

In $47 \%(112 / 239)$ of classical Hodgkin's lymphoma samples, the mean frequency of $\mathrm{p} 21^{\mathrm{CIP} 1}$ expression in Hodgkin and Reed-Sternberg cells per positive case was $15 \%$ (95\% confidence interval $14-19 \%$, standard deviation $\pm 22 \%$ ). Some of the tumor samples stained highly positive for $\mathrm{p} 21^{\mathrm{CIP} 1}$, giving rise to a wide variability of p21 $1^{\text {CIP1 }}$ expression in Hodgkin and Reed-Sternberg cells (Figure 1, Table 2). The staining intensity was moderate to strong and diffusely distributed throughout the nucleus (Figure 2a). Among the reactive lymphocytes surrounding Hodgkin and Reed-Sternberg cells, very few expressed $\mathrm{p} 21^{\mathrm{CIP} 1}$.

Of the classical Hodgkin's lymphoma cases, 47\% (116/249) expressed p27 $7^{\mathrm{KIP} 1}$ in $12 \%$ (mean frequency) of Hodgkin and Reed-Sternberg cells (95\% confidence interval 10-16\%, standard deviation $\pm 23 \%$ ) (Figure 1, Table 2). The staining intensity was weak to moderate and diffusely distributed throughout the nucleus (Figure 2b). The background reactive small lymphocytes expressed $\mathrm{p} 27^{\mathrm{KIP} 1}$ with a moderate to strong staining intensity in over $80 \%$ of the cell nuclei.

Of the classical Hodgkin's lymphomas, 99\% (250/ 253) expressed cyclin A in the vast majority of Hodgkin and Reed-Sternberg cells (mean frequency 98\%, 95\% confidence interval 97-99\%, standard deviation $\pm 14 \%$ ) (Figure 1, Table 2). Only in three tumor samples, Hodgkin and Reed-Sternberg cells were found to be negative for cyclin A. The staining intensity was strong and diffusely distributed throughout the nucleus (Figure 2c). Some surrounding lymphocytes stained positively with the anticyclin A antibody.

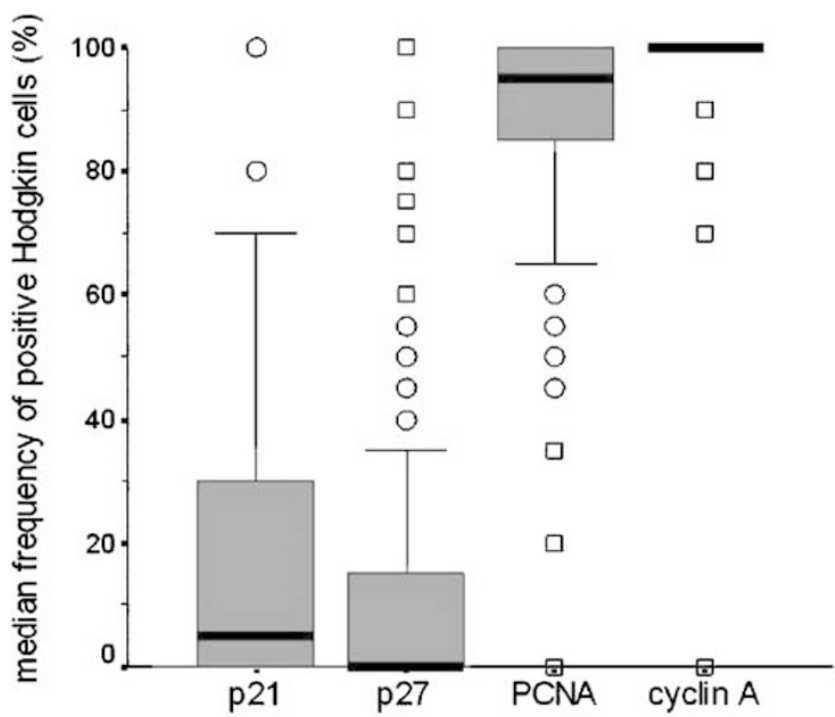

Figure 1 Median expression of the cell cycle regulating proteins p21 $1^{\mathrm{CIP} 1}, \mathrm{p} 27^{\mathrm{KIP} 1}$, PCNA and cyclin A in Hodgkin and ReedSternberg cells of classical Hodgkin's lymphoma, box-plot, the box length being the interquartile range, cases with values 1.5-3 (outliers $\bigcirc$ ) or $>3$ (extremes $\square$ ) box lengths from the upper or lower edge of the box are designated separately. p $21^{\mathrm{CIP} 1}$ median expression $5 \%$, mean $15 \%$, upper quartile $25 \%$, lower quartile $0 \%$, range $0-100 \%$; p $27^{\mathrm{KIP} 1}$ median expression $0 \%$, mean $12 \%$, upper quartile $15 \%$, lower quartile $0 \%$, range $0-100 \%$; PCNA median expression 95\%, mean 90\%, upper quartile 100\%, lower quartile $85 \%$, range $0-100 \%$; cyclin A median expression $100 \%$, mean expression $98 \%$, upper quartile $100 \%$, lower quartile $100 \%$. 
Table 2 p21 ${ }^{\mathrm{CIP} 1}$, p27 ${ }^{\mathrm{KIP} 1}$, PCNA and cyclin A expression in classical Hodgkin’s lymphoma: mean proportion of positive Hodgkin's and Reed-Sternberg cells

\begin{tabular}{|c|c|c|c|c|}
\hline \multirow{2}{*}{$\begin{array}{l}\text { Classical Hodgkin's lymphoma } \\
\text { subtype (n) }\end{array}$} & \multicolumn{4}{|c|}{ Mean proportion of positive Hodgkin and Reed-Sternberg cells (\%) ( $\mathrm{n}^{\text {positive }} / \mathrm{n}^{\text {evaluable }}$ cases) } \\
\hline & $p 21^{C I P 1}$ & $p 27^{K I P 1}$ & PCNA & Cyclin A \\
\hline Nodular sclerosis (147) & $15(55 / 136)$ & $11(57 / 142)$ & $90(141 / 141)$ & $98(143 / 146)$ \\
\hline Mixed cellularity (84) & $19(47 / 81)$ & $17(51 / 83)$ & $91(83 / 83)$ & $97(83 / 83)$ \\
\hline Lymphocyte-rich (9) & $13(2 / 8)$ & $11(3 / 9)$ & $66(8 / 8)$ & $100(9 / 9)$ \\
\hline Lvmphocyte-depleted (5) & $14(2 / 5)$ & $26(4 / 5)$ & $95(5 / 5)$ & $100(5 / 5)$ \\
\hline Unclassifiable (10) & $14(6 / 9)$ & $10(4 / 10)$ & $82(9 / 9)$ & $100(10 / 10)$ \\
\hline Total (255) & $15(112 / 239)$ & $12(116 / 249)$ & $90(246 / 246)$ & $98(250 / 253)$ \\
\hline
\end{tabular}
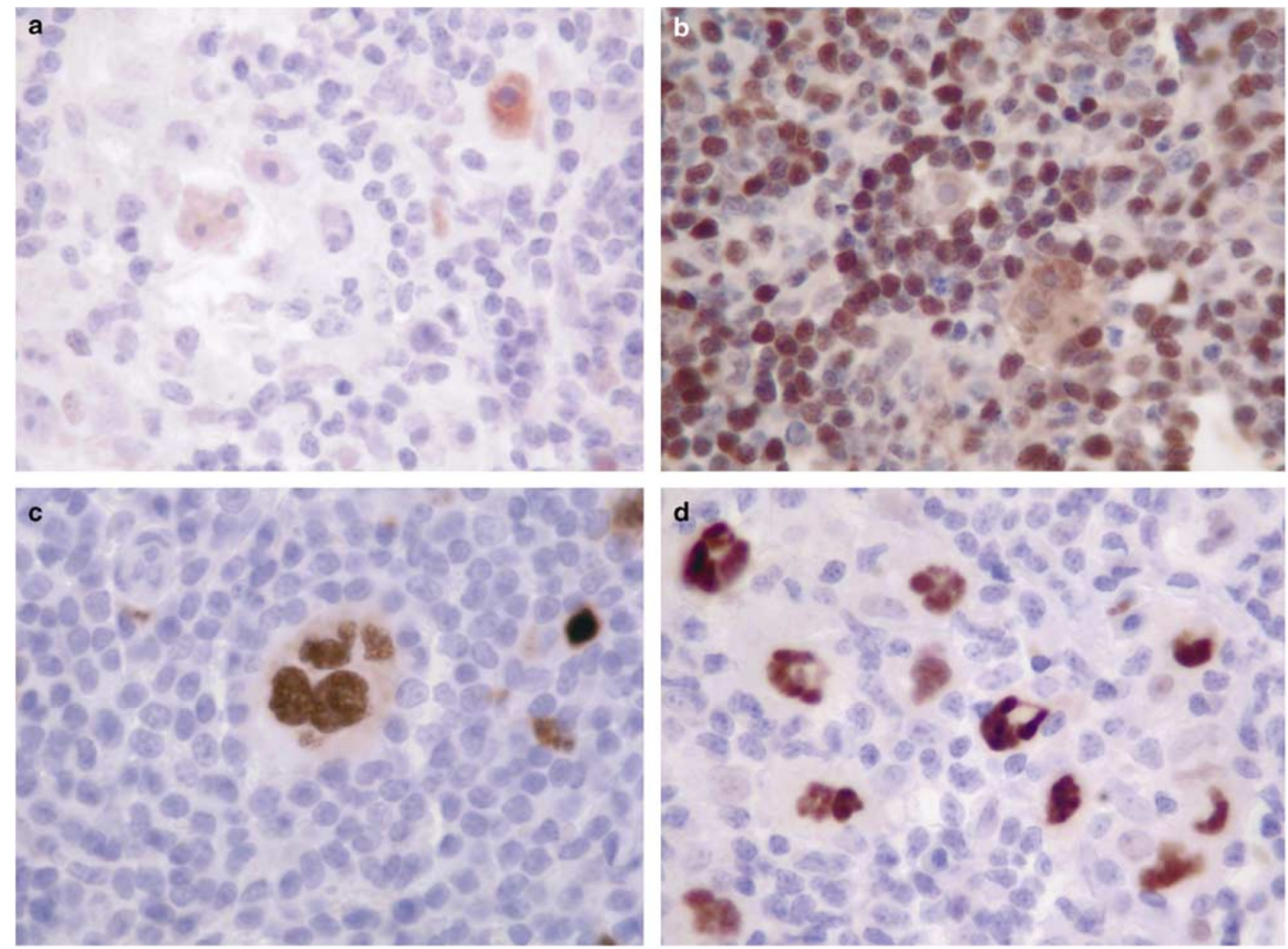

Figure 2 (a) Expression of p21 $1^{\mathrm{CIP} 1}$ in a Hodgkin cell. Note the negative surrounding lymphocytes as well as a negative Hodgkin cell (original magnification $\times 200$ ). (b) Expression of $\mathrm{p} 27^{\mathrm{KIP} 1}$ in a Reed-Sternberg cell. Note the strong staining intensity in surrounding lymphocyte nuclei (original magnification $\times 200$ ). (c) Expression of cyclin A in a Reed-Sternberg cell (original magnification $\times 250$ ). (d) Expression of proliferating cell nuclear antigen in Hodgkin and Reed-Sternberg nuclei (original magnification $\times 200$ ).

All 246 evaluable classical Hodgkin's lymphomas expressed PCNA in a mean proportion of $90 \%$ of Hodgkin and Reed-Sternberg cells (95\% confidence interval $87-91 \%$, standard deviation $\pm 16 \%$ ) (Figure 1, Table 2). PCNA staining was more variable than the staining for cyclin A. Only few surrounding lymphocytes were found to be positive for PCNA (Figure 2d).

The observed staining patterns in the reactive surrounding lymphocytes gave the expected staining 
patterns and frequencies, indicating that the antibodies and staining conditions employed in this study were appropriate for detection of these proteins.

\section{Statistical Analysis}

Statistical analysis (Table 3) revealed significant correlations between the expression of $\mathrm{p}^{2} 1^{\mathrm{CIP} 1}$ and p27 ${ }^{\mathrm{KIP} 1}(P<0.001)$ with $34 \%(80 / 235)$ of classical Hodgkin's lymphoma cases expressing both cyclindependent kinase inhibitors. Since the analysis of the expression of cyclin-dependent kinase inhibitors was performed on consecutive $4 \mu \mathrm{m}$ sections, making analysis of coexpression in single cells difficult, we statistically calculated that approximately 500 of the analyzed 10000 Hodgkin and Reed-Sternberg cells per slide (5\%) expressed both inhibitors. The expression of these proteins and their frequency suggests that these tumor cells are in $\mathrm{G}_{1}$-phase. PCNA expression, on the other hand, correlated with expression of cyclin A, with $99 \%$ (244/246) of classical Hodgkin's lymphoma cases being positive for both $(P=0.005)$. Approximately 9000 of the average 10000 Hodgkin and ReedSternberg cells present on every tissue microarray slide expressed cyclin A and PCNA, suggesting that more than $85 \%$ of these cells were in either $S$ - or $\mathrm{G}_{2}$-phase. As expected from our previous analysis, ${ }^{6}$ expression of PCNA also correlated with expression of cyclin D3 $(P=0.002)$ and cyclin E $(P<0.0001)$, suggesting that a significant fraction of $\mathrm{S}$-phase Hodgkin and Reed-Sternberg cells are positive for cyclin E.

Univariate analysis revealed a significantly higher frequency of treatment failures in patients with stage III and IV disease (16/36, 44\%) compared to those with stages I and II $(12 / 64,19 \%, P=0.006)$. The presence of B-symptoms correlated with clinical stage $(P=0.017)$. Patient age correlated with the different causes of death, that is, those younger than 45 years were more likely to succumb to lymphoma, whereas patients older than 45 years died of secondary malignancies or cardiovascular events $(P<0.0001)$.
Expression of the analyzed cell cycle regulatory proteins did not reach statistical significance for prognosis in classical Hodgkin's lymphoma, although only three of 54 patients expressing p $21^{\mathrm{CIP} 1}(6 \%)$ died of lymphoma, compared to six of 38 p21 ${ }^{\mathrm{CIP} 1}$-negative patients $(16 \%, P=0.075)$. Disease stage $(P=0.004)$ was of independent prognostic significance concerning failure-free survival in the multivariate analysis.

\section{Discussion}

Unlike most other malignant tumors, classical Hodgkin's lymphoma is not characterized by high numbers of proliferating tumor cells. In contrast, Hodgkin and Reed-Sternberg cells are sparse and surrounded by many activated non-neoplastic lymphocytes. Reed-Sternberg cells are multinucleated, while Hodgkin cells are often near triploid (reviewed in $\mathrm{Chan}^{19}$ ), which grow slowly in vitro (personal observations on HDLM-2 cell cultures). The slow growth phenotype of Hodgkin and ReedSternberg cells is accompanied by frequent mitotic defects as well as a high incidence of apoptosis. ${ }^{20}$ This suggests that Hodgkin and Reed-Sternberg cells might be actively proliferating cells that fail to accumulate due to an intrinsic failure to divide properly. Several proteins that regulate the mitotic cycle, such as cyclin D1, D3, E, B1, cyclin-dependent kinases 1, 2 and 6, S-phase kinase associated protein-2, p16 $6^{\mathrm{INK} 4 \mathrm{~A}}, \mathrm{p} 18^{\mathrm{INK} 4 \mathrm{c}}, \mathrm{p} 21^{\mathrm{CIP} 1}, \mathrm{p} 27^{\mathrm{KIP} 1}, \mathrm{p} 53$, the retinoblastoma protein and PCNA have been found to be deregulated in classical Hodgkin's lymphoma. ${ }^{1-4,6,20-26}$

In the present study, we used a previously validated classical Hodgkin's lymphoma tissue microarray with a cohort of clinically well-documented cases $^{6,17,27}$ to analyze the expression of the cyclin-dependent kinase inhibitors of the Cip/Kipfamily, p2 $1^{\mathrm{CIP} 1}$ and $\mathrm{p} 27^{\mathrm{KIP} 1}$, as well as two proliferation markers, PCNA and cyclin A. Since Hodgkin and Reed-Sternberg cells are embedded within reactive normal lymphocytes, we used those lymphocytes as internal controls for our staining

Table 3 Correlations between expression of p21 ${ }^{\mathrm{CIP} 1}$, p2 $7^{\mathrm{KIP} 1}$, PCNA, $\mathrm{G}_{1}$-cyclins and the latent membrane protein 1 of Epstein-Barr virus (LMP1) in classical Hodgkin's lymphoma ( $P$-values (upper) and correlation coefficients (lower))

\begin{tabular}{|c|c|c|c|c|c|c|c|}
\hline $\mathrm{p} 27^{\mathrm{KIP} 1}$ & $\begin{array}{r}<0.001 \\
0.208\end{array}$ & & & & & & \\
\hline PCNA & - & - & & & & & \\
\hline LMP1 & - & - & - & & & & \\
\hline Cyclin A & - & - & $\begin{array}{l}0.005 \\
0.181\end{array}$ & - & & & \\
\hline Cyclin D1 & $\begin{array}{l}0.034 \\
0.141\end{array}$ & - & - & - & - & & \\
\hline Cyclin D3 & - & - & $\begin{array}{l}0.002 \\
0.194\end{array}$ & $\begin{array}{l}0.006 \\
0.173\end{array}$ & $\begin{array}{l}0.018 \\
0.150\end{array}$ & $\begin{array}{l}0.003 \\
0.187\end{array}$ & \\
\hline Cyclin E & $\begin{array}{c}<0.0001 \\
0.264\end{array}$ & - & $\begin{array}{c}<0.0001 \\
0.271\end{array}$ & - & - & $\begin{array}{l}0.016 \\
0.151\end{array}$ & $\begin{array}{c}<0.0001 \\
0.224\end{array}$ \\
\hline & $\mathrm{p} 21^{\mathrm{CIP} 1}$ & $\mathrm{p} 27^{\mathrm{KIP} 1}$ & PCNA & LMP1 & cyclin A & cyclin D1 & cyclin D3 \\
\hline
\end{tabular}


conditions. As expected, most of these lymphocytes stained strongly for $\mathrm{p} 27^{\mathrm{KIP} 1}$, while only a few stained for PCNA or cyclin A, suggesting that they are in the $\mathrm{G}_{1}$-phase of the cell cycle. p21 ${ }^{\mathrm{CIP} 1}$ was hardly detectable in these lymphocytes. In Hodgkin and Reed-Sternberg cells, however, we found significant divergences from the expected expression frequency of cyclin-dependent kinase inhibitors, PCNA and cyclin A.

In normal, as well as transformed, human cells, cyclin A becomes detectable at the onset of the $\mathrm{S}$-phase, accumulates throughout $\mathrm{S}$ - and $\mathrm{G}_{2}$-phase, and then rapidly declines in early mitosis (reviewed in Gillett and Barnes, ${ }^{13}$ den Elzen and Pines ${ }^{15}$ and Geley et $\mathrm{al}^{16}$ ). Cyclin A can, therefore, be regarded as a marker of proliferation, since only cells in S- and $\mathrm{G}_{2}$-phase or early mitosis stain positively with anticyclin $A$ antibodies, while cells in $\mathrm{G}_{1}$-phase remain negative. We found cyclin A expression in $98 \%$ of the Hodgkin and Reed-Sternberg cells in nearly all (99\%) analyzed classical Hodgkin's lymphoma cases, suggesting that most of the tumor cells are in either S- or $\mathrm{G}_{2}$-phase of the cell cycle. This hypothesis was corroborated by PCNA staining experiments using our classical Hodgkin's lymphoma tissue microarray, which showed that $90 \%$ of Hodgkin and Reed-Sternberg cells were positive. Because PCNA is mainly expressed in S-phase cells, we conclude that the majority of Hodgkin and ReedSternberg cells are either in S- or $\mathrm{G}_{2}$-phase of the cell division cycle. Our data confirm previously published data ${ }^{2-4,22,24}$ reporting high expression of PCNA and Ki-67 in classical Hodgkin's lymphoma.

The cyclin-dependent kinase inhibitors p27 ${ }^{\mathrm{KIP} 1}$ and p21 ${ }^{\mathrm{CIP} 1}$ were rarely expressed in Hodgkin and Reed-Sternberg cells, and such expression correlated well with each other as well as with the expression of $G_{1}$-cyclins, suggesting that these few cells were in $\mathrm{G}_{1}$-phase. In contrast to our data, Garcia et $a l^{22}$ and Ohshima et $a l^{25}$ reported higher expression of $\mathrm{p} 27^{\mathrm{KIP} 1}$ and $\mathrm{p} 21^{\mathrm{CIP} 1}$ in their classical Hodgkin's lymphoma samples. However, Garcia et al applied other primary anti-p27 $7^{\mathrm{KIP} 1}$ antibodies, and Ohshima et al determined the expression of p $21^{\mathrm{CIP} 1}$ on frozen classical Hodgkin's lymphoma tissue samples, which might explain some of the differences. Our observed low expression levels of p21 ${ }^{\mathrm{CIP} 1}$ and $\mathrm{p} 27^{\mathrm{KIP} 1}$ is in agreement with reports by other authors. ${ }^{3,23,24}$

Our data suggest that about $80-90 \%$ of Hodgkin and Reed-Sternberg cells are in S- or $\mathrm{G}_{2}$-phase, while only about $10-20 \%$ are in $\mathrm{G}_{1}$-phase. Surprisingly, however, we could only count 57 mitoses in 10243 cells analyzed. This low mitotic index (0.5\%) suggests that Hodgkin and Reed-Sternberg cells either do not enter mitosis or rapidly die in mitosis. Concerning the overexpressed $\mathrm{G}_{1}$-cyclins, including cyclin E, in Hodgkin's lymphoma , our present data suggest that their accumulation may be caused by reduced proteolysis, rather than being a reflection of typical cell cycle-dependent expression levels.
Hodgkin and Reed-Sternberg cells have large nuclei indicative of higher DNA content and, in our study, $20 \%$ exhibited a multinuclear ReedSternberg phenotype. In contrast to micronuclei, which are not observed in Hodgkin and ReedSternberg cells, and which are caused by chromosome malsegregation during mitosis, multinucleation is caused by cytokinesis defects or cell fusion. Kuppers et $a l^{28}$ have investigated the mechanism leading to multinucleation in Hodgkin and ReedSternberg cells and reported that it is not caused by cellular fusion. The large nuclei present in Hodgkin and Reed-Sternberg cells may, therefore, be caused by cytokinesis defects or by DNA over-replication. Whether the former or the latter underlies the aberrant morphology and biology of Hodgkin and Reed-Sternberg cells is an important unresolved issue. Expression of cyclin E is required for endoreduplication in trophoblasts ${ }^{29}$ as well as in megakaryocytes $^{30}$ and overexpression of cyclin $\mathrm{E}$ has been correlated with polyploidy and chromosome instability in human tumors (Hubalek et $a l^{31}$ and references therein). Whether and how overexpression of cyclin A might contribute to the cell cycle abnormalities observed in Hodgkin and ReedSternberg cells is not clear at the moment. Overexpression of cyclin A has been shown to impede progression through mitosis and might facilitate apoptosis. ${ }^{32}$ The expression of cell cycle regulatory proteins in malignant tumors is often analyzed to obtain prognostic information. High expression of proliferation markers, including Ki-67, PCNA, cyclin A and others, often have been associated with poor prognosis due to the high proliferation rate of the tumors. In classical Hodgkin's lymphoma, however, we found no association between cell cycle markers and clinical outcome. Again, this reflects the atypical nature of this disease, the pathology of which is not caused by rapid accumulation of malignant cells, but rather by the accumulation of reactive lymphocytes and perturbation of the cellular and humoral immunity (reviewed in Skinnider and $\mathrm{mak}^{33}$ ). We found a weak correlation between $\mathrm{p} 21^{\mathrm{CIP} 1}$ expression and disease-specific survival, which may be caused by induction of p53-dependent apoptotic pathways in a subset of classical Hodgkin's lymphomas. ${ }^{21,34}$

In summary, our study has shown that the majority of reactive lymphocytes surrounding the tumor cells of classical Hodgkin's lymphoma are in $\mathrm{G}_{1}$-phase, while the majority of Hodgkin and ReedSternberg cells appear to be either in S- or $\mathrm{G}_{2}$-phase of the cell cycle. These data argue that selfreplication of Hodgkin and Reed-Sternberg cells is futile with cells unable to divide properly. Rather, these cells acquire polyploidy due to possible defects in cytokinesis or activation of endomitotic cycles causing over-replication of DNA. Further in vitro studies using classical Hodgkin's lymphoma derived cell lines will distinguish between these possibilities. 


\section{Acknowledgements}

This work was supported by Krebshilfe Tirol (to AT), FWF Grant No. P15000 (to SG) and an AIRC grant (to SAP).

\section{References}

1 Leoncini L, Megha T, Lazzi S, et al. Cellular kinetic differences between Hodgkin's and anaplastic large cell lymphomas: relation to the expression of p34cdc2 and cyclin B-1. Int J Cancer 1998;77:408-414.

2 Spina D, Leoncini L, Close P, et al. Growth vs DNA strand breaks in Hodgkin's disease: impaired proliferative ability of Hodgkin and Reed-Sternberg cells. Int J Cancer 1996;66:179-183.

3 Kanavaros $\mathrm{P}$, Stefanaki K, Vlachonikolis J, et al. Expression of p53, p21/waf1, bcl-2, bax, Rb and Ki-67 proteins in Hodgkin's lymphomas. Histol Histopathol 2000;15:445-453.

4 Schmid C, Sweeney E, Isaacson PG. Proliferating cell nuclear antigen (PCNA) expression in Hodgkin's disease. J Pathol 1992;168:1-6.

5 Zimmet J, Ravid K. Polyploidy: occurrence in nature, mechanisms, and significance for the megakaryocyteplatelet system. Exp Hematol 2000;28:3-16.

6 Tzankov A, Zimpfer A, Lugli A, et al. High-throughput tissue microarray analysis of G1-cyclin alterations in classical Hodgkin's lymphoma indicates overexpression of cyclin E1. J Pathol 2003;199:201-207.

7 Blain SW, Montalvo E, Massague J. Differential interaction of the cyclin-dependent kinase (Cdk) inhibitor p27Kip1 with cyclin A-Cdk2 and cyclin D2-Cdk4. J Biol Chem 1997;272:25863-25872.

8 Dotto GP. p21(WAF1/Cip1): more than a break to the cell cycle? Biochim Biophys Acta 2000;1471:43-56.

9 Dulic V, Stein GH, Far DF, et al. Nuclear accumulation of p21Cip1 at the onset of mitosis: a role at the G2/Mphase transition. Mol Cell Biol 1998;18:546-557.

10 Sherr CJ, Roberts JM. CDK inhibitors: positive and negative regulators of G1-phase progression. Genes Dev 1999;13:1501-1512.

11 D’Angiolella V, Costanzo V, Gottesman ME, et al. Role for cyclin-dependent kinase 2 in mitosis exit. Curr Biol 2001;11:1221-1226.

12 Sheaff RJ, Groudine M, Gordon M, et al. Cyclin ECDK2 is a regulator of p27Kip1. Genes Dev 1997;11: 1464-1478.

13 Gillett CE, Barnes DM. Demystified ... cell cycle. J Clin Pathol: Mol Pathol 1998;51:310-316.

14 Sherr CJ. The Pezcoller lecture: cancer cell cycles revisited. Cancer Res 2000;60:3689-3695.

15 den Elzen N, Pines J. Cyclin A is destroyed in prometaphase and can delay chromosome alignment and anaphase. J Cell Biol 2001;153:121-136.

16 Geley S, Kramer E, Gieffers C, et al. Anaphasepromoting complex/cyclosome-dependent proteolysis of human cyclin A starts at the beginning of mitosis and is not subject to the spindle assembly checkpoint. J Cell Biol 2001;153:137-148.

17 Tzankov A, Zimpfer A, Pehrs A, et al. Expression of Bcell markers in classical Hodgkin's lymphoma: a tissue microarray analysis of 330 cases. Mod Pathol 2003;16: 1141-1147.
18 Stein H, Delsol G, Pileri S, et al. Classical Hodgkin's lymphoma. In: Jaffe ES, Harris NL, Stein H, Vardiman JW (eds). Pathology and Genetics of Tumours of the Haematopoietic and Lymphoid System. IARC Press: Lyon, 2001, pp 244-253.

19 Chan WC. The Reed-Sternberg cell in classical Hodgkin's disease. Hematol Oncol 2001;19:1-17.

20 Lorenzen J, Thiele J, Fischer R. The mummified Hodgkin cell: cell death in Hodgkin's disease. J Pathol 1997;182:288-298.

21 Elenitoba-Johnson KS, Medeiros LJ, Khorsand J, et al. p53 expression in Reed-Sternberg cells does not correlate with gene mutations in Hodgkin's disease. Am J Clin Pathol 1996;106:728-738.

22 Garcia JF, Camacho FI, Morente M, et al. Hodgkin and Reed-Sternberg cells harbor alterations in the major tumor suppressor pathways and cell-cycle checkpoints: analysis using tissue microarrays. Blood 2003;101:681-689.

23 Kolar Z, Flavell JR, Ehrmann J, et al. Apoptosis of malignant cells in Hodgkin's disease is related to expression of the cdk inhibitor p27KIP1. J Pathol 2000;190:604-612.

24 Naresh KN, O’Conor GT, Soman CS, et al. A study of p53 protein, proliferating cell nuclear antigen, and p21 in Hodgkin's disease at presentation and relapse. Hum Pathol 1997;28:549-555.

25 Ohshima K, Haraoka S, Fujiki T, et al. Expressions of cyclin E, A, and B1 in Hodgkin and Reed-Sternberg cells: not suppressed by cyclin-dependent kinase inhibitor p21 expression. Pathol Int 1999;49: 506-512.

26 Sanchez-Aguilera A, Delgado J, Camacho FI, et al. Silencing of the p18INK4c gene by promoter hypermethylation in Reed-Sternberg cells in Hodgkin's lymphomas. Blood 2004;103:2351-2357.

27 Tzankov A, Krugmann J, Fend F, et al. The prognostic significance of CD20 expression in classical Hodgkin's lymphoma-a clinico-pathological study of 119 cases. Clin Cancer Res 2003;9:1381-1386.

28 Kuppers R, Brauninger A, Muschen M, et al. Evidence that Hodgkin and Reed-Sternberg cells in Hodgkin disease do not represent cell fusions. Blood 2001;97: 818-821.

29 Parisi T, Beck AR, Rougier N, et al. Cyclins E1 and E2 are required for endoreplication in placental trophoblast giant cells. EMBO J 2003;22:4794-4803.

30 Garcia P, Frampton J, Ballester A, et al. Ectopic expression of cyclin E allows non-endomitotic megakaryoblastic K562 cells to establish re-replication cycles. Oncogene 2000;19:1820-1833.

31 Hubalek MM, Widschwendter A, Erdel M, et al. Cyclin E dysregulation and chromosomal instability in endometrial cancer. Oncogene 2004;23:41874192.

32 Meikrantz W, Gisselbrecht S, Tam SW, et al. Activation of cyclin A-dependent protein kinases during apoptosis. Proc Natl Acad Sci USA 1994;91: 3754-3758.

33 Skinnider BF, Mak TW. The role of cytokines in classical Hodgkin's lymphoma. Blood 2002;99: 4283-4297.

34 Montesinos-Rongen M, Roers A, Kuppers R, et al. Mutation of the p53 gene is not a typical feature of Hodgkin and Reed-Sternberg cells in Hodgkin's disease. Blood 1999;94:1755-1760. 